\title{
TRABAJO SOCIAL INDIVIDUALIZADO: METODOLOGÍA DE INTERVENCIÓN ${ }^{8}$
}

\author{
Tomás Fernández García ${ }^{9}$ \\ Laura Ponce de León Romero ${ }^{10}$
}

Con un lenguaje claro y conciso, en este trabajo se analizan los grandes problemas que atraviesan las personas a lo largo de su vida, porque según sus autores, todos en algún momento de nuestra existencia debemos soportar desdichas, grandes o pequeñas, crueles o trágicas, que finalmente se convierten en traumatismos emocionales difíciles de curar. Por ejemplo, la muerte de los seres queridos, el dolor que supone la emigración, el temor a ser deportado por la situación irregular, la separación de la persona a la que se ama, la aparición de los problemas económicos como consecuencia del desempleo, la violencia doméstica, el deterioro de la seguridad del niño o del joven como consecuencia del abandono escolar, los conflictos con la familia, o el fracaso de un nuevo proyecto.

En ocasiones, los problemas de la vida dependen de cómo lo encare la propia persona, quien puede decidir superarlos por sí misma, o por el contrario, puede convertirse en un ser resentido y amargado ante las injusticias del mundo. Otras veces, se sienten tan castigadas que son incapaces de salir por sí solas de las situaciones tan dramáticas que tienen que soportar en su vida cotidiana. Ante cualquier adversidad, siempre se puede actuar, reflexionar, compartir y cambiar, se puede elegir un nuevo camino para rehacerse o para convertir las crisis en oportunidades, siempre que tenga como objetivo salir de los grandes o pequeños problemas, pero aun así, existen millones de personas que se sienten indefensas y frágiles para enfrentarse a un mundo conflictivo y cambiante, en el que se experimentan más frustraciones que satisfacciones, y en el que

\footnotetext{
${ }^{8}$ Ediciones Académicas, España, 2012, ISBN 978-84-92477-57-9

${ }^{9}$ Profesor, Universidad de Educación a Distancia de España.

${ }^{10}$ Profesora, Universidad de Educación a Distancia de España.
} 
se sienten incapaces de cubrir sus necesidades más básicas, y vulnerables porque no se les ha ofrecido la oportunidad de conquistar ni el pasado, ni el presente, ni el futuro, adoptando finalmente una postura de resignación y abandono que terminará marcando el devenir de sus días.

En el libro se proponen alternativas metodológicas que ayudan a atenuar los sufrimientos individuales, que movilizan los recursos para orientarlos hacia un cambio positivo a pesar del drama sufrido, donde el trabajo social individualizado se convierte frente a estos problemas en un proceso educativo y social dirigido hacia la persona objeto de intervención, para que pueda superar sus necesidades, incrementando sus fortalezas, sus habilidades y destrezas. La lectura del libro facilita a la persona objeto de intervención, a aprender de las derrotas, a reconstituirse creativamente, a percibir sus dificultades como desafíos, a ser más fuerte, a pensar, a cambiar el punto de vista personal para hacerlo más amplio y flexible, a buscar soluciones, y finalmente, a actuar por sí solo para mejorar sus condiciones de vida.

La práctica del trabajo social individualizado desarrollada ampliamente en las páginas, conlleva un proceso que delimita lo que hay qué hacer, cómo hacerlo, y en qué orden, con el objetivo de conseguir que la persona pueda sortear los obstáculos que entorpecen su vida familiar, personal, y resolver los dilemas creados en sus relaciones interpersonales. Se tratan grandes conflictos, ofreciendo respuestas válidas desde un paradigma teórico basado en años de experiencia práctica en la intervención individualizada. Se proporcionan modelos, funciones, valores, principios, métodos y procedimientos operativos que se han desarrollado a lo largo de los años, con el propósito de crear un pensamiento constructivo para que la persona pueda afrontar las adversidades, superarlas y salir de ellas fortalecida e, incluso, transformada para proyectar autónomamente su futuro.

Para que sea comprensible su lectura, en cada capítulo se recogen objetivos, resumen, actividades de repaso, preguntas de recapitulación, lecturas recomendadas, un glosario en el que se definen algunos términos más importantes del libro, además de un caso práctico analizado desde ocho modelos distintos que hacen comprensible el problema expuesto.

Por: Francisco Javier García Castilla, Profesor

Universidad Nacional de Educación a Distancia, España 